\title{
AS ESPIRITUALIDADES EM PSICOTERAPEUTAS JUNGUIANOS E TRANSPESSOAIS: UM BREVE ESTUDO FENOMENOLÓGICO
}

\author{
Spiritualities in Jungian and Transpersonal Psychotherapists: A Brief Phenomenological Study \\ Las espiritualidades en psicoterapeutas junguianos y transpersonales: un breve estudio fenom- \\ enológico \\ Aurino L. FERreira \\ LAILA A. C. SILVA \\ SIDNEY C. R. SILVA \\ MARLOS A. BEZERRA
}

\begin{abstract}
Resumo: A espiritualidade enquanto fenômeno humano apresenta-se como aspecto significativo na compreensão e promoção de saúde, contudo seu estudo foi negligenciado pelas teorias psicológicas, com exceção dos estudos pioneiros de Jung e da abordagem transpessoal. Neste sentido, objetivamos apresentar a visão de espiritualidade de psicólogos da cidade do Recife (PE) que se orientam por estas linhas teóricas, indicando como esse fenômeno é vivenciado em suas práticas profissionais. Realizamos uma pesquisa qualitativa de cunho fenomenológico e que teve como instrumento a entrevista semiestruturada com oito psicólogos. Os dados foram analisados segundo a abordagem fenomenológica de Bicudo e encontram-se em consonância com a literatura científica da área, que aponta não haver uma definição hegemônica sobre espiritualidade. Há visões de espiritualidades, às vezes singulares, outras vezes comuns. A espiritualidade aparece por vezes como sinônimo de amor incondicional, ora desponta como acesso ao que é transcendente, sem negar a imanência. Surge como energia interna e acesso ao Eu superior/Self. Na clínica ela é considerada como promotora de saúde e abordada a partir da demanda na perspectiva junguiana e vista como contextual na transpessoal. Levantamos reflexões sobre a importância da espiritualidade na compreensão do ser humano em sua complexidade.
\end{abstract}

Palavras-chave: Espiritualidade; Psicologia junguiana; Psicologia transpessoal; Clínica psicológica.

\begin{abstract}
Spirituality as a human phenomenon presents itself as a significant aspect in the understanding and promotion of health, yet its study was neglected by psychological theories, with the exception of Jung's pioneering studies and the transpersonal approach. In this sense, we aim to present the vision of spirituality among psychologists from the city of Recife (in Brazil) who are guided by these theoretical lines, indicating how this phenomenon is experienced in their professional practices. We performed a phenomenological qualitative research that had as instrument the semi-structured interview with eight psychologists. The data were analyzed according to Bicudo's phenomenological approach and are in agreement with the scientific literature in this field, which indicates that there is no hegemonic definition of spirituality. There are visions of spiritualities, sometimes singular, sometimes common. Spirituality sometimes appears as synonymous with unconditional love, sometimes as access to the transcendent, without denying immanence. It also arises as internal energy and access to the Higher Self or just the Self. In the clinic it is considered as health promoter and approached from the demand in the Jungian perspective and seen as contextual in the transpersonal. We raised reflections on the importance of spirituality to the understanding of human being in its complexity.
\end{abstract}

Keywords: Spirituality; Jungian psychology; Transpersonal psychology; Psychological clinic.

Resumen: La espiritualidad como fenómeno humano se presenta como un aspecto significativo en la comprensión y promoción de la salud. No obstante, su estudio fue descuidado por las teorías psicológicas, con la excepción de los estudios pioneros de Jung y del enfoque transpersonal. En este sentido, objetivamos presentar la visión sobre la espiritualidad de los psicólogos de la ciudad de Recife (Brasil) orientados por estas líneas teóricas, indicando cómo ese fenómeno es vivenciado en sus prácticas profesionales. Realizamos una investigación cualitativa de cuño fenomenológico teniendo como instrumento entrevistas semiestructuradas con la participación de ocho psicólogos. Los datos fueron analizados según el enfoque fenomenológico de Bicudo y se encuentran en consonancia con la literatura científica del área, que apunta no haber una definición hegemónica sobre la espiritualidad. Hay visiones de espiritualidad, a veces singulares, otras veces comunes. La espiritualidad aparece en algún momento como sinónimo de amor incondicional y en otros como acceso a lo que es trascendente, sin negar la inmanencia. Se presenta como energía interna y acceso al Yo Superior/Self. En la clínica ella es considerada como promotora de salud y abordada a partir de la demanda en la perspectiva junguiana y vista como contextual en la transpersonal. Levantamos reflexiones sobre la importancia de la espiritualidad en la comprensión del ser humano en su complejidad.

Palabras clave: Espiritualidad; Psicología junguiana; Psicología transpersonal; Clínica psicológica 


\section{Introdução}

O "momento cartesiano" (Foucault, 2006), promovido pela modernidade, instaurou no mundo ocidental a lógica da separatividade e reforçou a visão reducionista de que o humano pode ser compreendido exclusivamente através do racionalismo que exclui uma visão multidimensional e integral que toma o fenômeno humano a partir de uma perspectiva biopsicossocial e espiritual.

Neste contexto, a dimensão espiritual foi particularmente execrada, pois se confundia com religião, não podendo, portanto, fazer parte de uma agenda de investigação acadêmica, amplamente pautada no cientificismo. Contudo, em um mundo complexo e plural, novas perspectivas de ciência foram requeridas, o que vem favorecendo a entrada da temática da espiritualidade no cenário do debate acadêmico, conforme demonstra Koenig (2005) que aponta um "aumento de mais de 600\%" (p. 6) das publicações, nesta área, desde os anos 70.

Assim, a literatura acadêmica no campo psicológico vem gradativamente apontando a importância da inclusão da espiritualidade nos processos de acompanhamento terapêutico (Cambuy, Baungarte \& Amatuzzi, 2007; Freitas \& Vilela, 2017; Moreira-Almeida, 2010; Moreira-Almeida, Lotufo-Neto \& Koenig, 2006; Panzini \& Bandeira, 2007). Peres, Simão e Nasello (2007) apontam as contribuições da Associação Psiquiátrica Americana (APA) para o manejo desta temática por parte dos terapeutas, sinalizando que o seu reconhecimento favorece a adesão e ampliação das possibilidades de cuidado.

De maneira geral, os estudos indicam que a espiritualidade “(...) pode ser entendida como uma busca pessoal por significado e sentido maior no existir e sua relação com o sagrado e o transcendente, podendo estar vinculada ou não a uma religião formalizada ou designação religiosa.” (Dal-Farra \& Geremia, 2010, p. 588). Esses autores nos apontam para uma busca de um para "além de", algo que transcende e que dá sentido ao existir. Algo que não é religião, mas pode ser, depende de quem a vivencia e como vivencia. Corroborado por Vasconcelos (2009) quando aponta que a espiritualidade:

É um conceito que ressalta principalmente a dinâmica de aproximação com o eu profundo, que não corresponde necessariamente aos caminhos padronizados difundidos pelas hierarquias religiosas tradicionais. Mesmo líderes religiosos, como Boff (1999), afirmam que o decisivo não são as religiões, mas a espiritualidade subjacente a elas (pp. 330-331).

Panzini, Rocha, Bandeira e Fleck (2007) destacam que "o termo espiritualidade envolve questões quanto ao significado da vida e à razão de viver, não limitado a tipos de crenças ou práticas” (p.106). A religião, por sua vez, pode ser um meio para a espiritualidade, mas descarta-se a possibilidade de ser o fim. Neste sentido, Vasconcelos (2009) indica-nos que: "Encontra-se aí a força da espiritualidade como instrumento de promoção da saúde, na medida em que lida com as dimensões pouco conscientes do ser em que se assentam os valores, motivações profundas e sentidos últimos da existência individual e coletiva” (p. 325). Xavier (2006) nos aponta outra questão quanto à espiritualidade, diferenciando esse conceito de religiosidade, conceitos próximos, mas que são confundidos em alguns momentos.

"Religiosidade" tende a denotar um sentido mais estrito, vinculado à religião institucional; e "espiritualidade" tende a ser diferenciada de religião em função de um sentido (ou conotação) mais individual ou subjetivo de experiência do sagrado. Exemplo significativo, o próprio Diagnostic and Statistical Manual of Mental Disorders (DSM-IV) veio a distinguir problemas religiosos de problemas espirituais. (Xavier, 2006, p. 183, itálicos nossos).

Com esse pequeno recorte sobre o tema, vemos que há uma tentativa, por parte dos autores do campo psi, em apresentar distinções entre espiritualidade, religião e religiosidade, contudo, como apontam Freitas e Vilela (2017) não há uma necessidade de reatualizarmos antigas cisões e antagonismos irreconciliáveis quando trabalhamos com estes termos, pois as suas intersecções no mundo vivido requerem uma leitura complexa e integrativa por parte da psicologia. Neste artigo tomamos a espiritualidade como um “(...) movimento subjetivo com o qual o homem se expõe além dos confins da própria existência terrena e da experiência fenomênica, com uma atitude de esperança, de busca e/ou de atribuição de sentido" (Aletti, 2012, p. 166).

Assim, levantadas algumas perspectivas sobre o que se compreende sobre a espiritualidade em produções acadêmicas e levando-se em conta que o IBGE (2012) aponta que aproximadamente 92\% da população brasileira declara ter algum vínculo com uma religião formal, questiona-se: como cuidar do humano sem levar em consideração a sua espiritualidade? Como falar de integralidade na saúde sem mencionar o espiritual? Como a Psicologia, uma ciência que se propõe cuidar, (não) tem pensado nessa dimensão do humano?

Estas questões são foco de intensos debates no cenário das áreas de saúde, assim como faz parte dos debates promovidos no âmbito do sistema de conselhos que apontam a necessidade de ampliação de interfaces com as múltiplas dimensões do fenômeno humano. Isto foi materializado na Coleção "Psicologia, Laicidade e as Relações com a Religião e a Espiritualidade" (CRPSP, 2016) que aborda esta temática de maneira multivariada. 
Historicamente, no campo acadêmico da psicologia, a temática da espiritualidade foi tratada, de forma mais anunciada e desvelada, pelas linhas teóricas da Psicologia Junguiana e da Psicologia Transpessoal que anteciparam em suas agendas de pesquisa o estudo desta temática. Desta forma, neste trabalho questionamos: como terapeutas que se norteiam pelas linhas teóricas da psicologia junguiana e transpessoal compreendem o fenômeno da espiritualidade nos seus processos de formação enquanto psicoterapeutas e dentro de suas práticas profissionais?

Assim, entendendo ser fundamental o estudo da espiritualidade no processo de formação dos profissionais da psicologia, objetivamos apresentar a visão de psicólogos junguianos e transpessoais da cidade do Recife (PE) sobre espiritualidade, discutindo como compreendem e lidam com esta temática em suas práticas profissionais. Para tanto, organizamos o corpo deste texto da seguinte maneira: apresentamos inicialmente uma breve visão sobre a espiritualidade nas abordagens junguiana e transpessoal; posteriormente, situamos o corte metodológico de cunho fenomenológico, seguido da apresentação dos resultados e considerações gerais.

\section{Reflexões sobre espiritualidade nas abordagens junguiana e transpessoal}

\section{Visão junguiana da espiritualidade}

A psicologia analítica surge inseparável das buscas de seu criador, Carl Jung, pelo "lado espiritual”.

Olhando para trás, posso dizer que sou o único que prosseguiu os estudos dos dois problemas que mais interessavam a Freud: o dos 'resíduos arcaicos e o da sexualidade'. Espalhou-se o erro que não vejo valor da sexualidade. Muito pelo contrário, ela desempenha um grande papel em minha psicologia, principalmente como expressão fundamental - mas não a única - da totalidade psíquica. Minha preocupação essencial era, no entanto, aprofundar a sexualidade, além do seu significado pessoal e seu alcance de função biológica, explicando-lhe o seu lado espiritual e o sentido numinoso. Exprimia, assim, o que fascinara Freud, sem que este o compreendesse. (Jung, 2006, p. 50).

Em entrevista à BBC de Londres, no programa Face a face com John Freeman, quando questionado sobre a religiosidade e sua crença em Deus, Jung afirma que o conhece, sinalizando que:

Quando digo que não preciso acreditar em Deus porque o "conheço", quero dizer que conheço a existência da imagem de Deus em geral e em particular. Sei que esta é uma questão de experiência universal e, na medida em que não sou a exceção, sei que também tenho essa experiência que chamo de Deus. É a experiência de minha vontade com outra vontade, quase sempre mais forte, que cruza meu caminho, muitas vezes com resultados desastrosos, colocando ideias estranhas na minha cabeça e manobrando meu destino às vezes para regiões indesejáveis ou dando-lhes inesperadas reviravoltas favoráveis, sem meu conhecimento ou minha intenção. Conheço bem essa força estranha que se manifesta contra ou a favor de minhas tendências conscientes. Por isso digo: "Eu O conheço." Mas por que você chama isso de "Deus"? Eu respondo: "Por que não?" Sempre o chamaram de "Deus”. (Dunne, 2012, p. 230).

Nos seus estudos sobre religião, Jung (1995) a divide em dois grandes sentidos. Primeiro, temos este termo se referindo uma confissão que toma sua origem numa profissão de fé determinada e dogmática, algo que neste trabalho denominamos de religião e, de outro lado, aborda este fenômeno como uma experiência ou uma série de experiências primordiais, nas quais o humano entra em relação com um sagrado que provoca nele o sentimento do numinoso, que aqui denominamos de espiritualidade.

Carl Jung reconhecia a importância da espiritualidade no processo psicoterapêutico, assim como incluía em seu trabalho reflexões sobre como este fenômeno afetava a vida psíquica de seus pacientes.

Entre todos os meus doentes na segunda metade da vida, isto é, tendo mais de 35 anos, não houve um só cujo problema mais profundo não fosse constituído pela questão de sua atitude religiosa. Todos, em última instância, estavam doentes por ter perdido aquilo que uma religião viva sempre deu em todos os tempos a seus adeptos, e nenhum curou-se realmente sem recobrar a atitude religiosa que lhe fosse própria. Isto, é claro, não depende absolutamente de adesão a um credo particular ou de tornar-se membro de uma igreja (Jung, 1995, pp.153-154).

Assim, na religiosidade ou espiritualidade em Jung (1998) “(...) o que importa já não são os dogmas e credos, mas sim toda uma atitude religiosa, que tem uma função psíquica de incalculável alcance” (p. 44), pois favorece o processo de individuação, ou seja, permite-nos realizar o nosso potencial através da integração do material inconsciente à consciência.

Jung (1982) fala de um humano que pode ser um pouco do tudo/todo que se é, mas que se individua num processo constante de ser em busca do Self que compreende o que se pode chama de mais profundo eu. Nesta perspectiva, a espiritualidade esta irremediavelmente ligada à noção do inconsciente coletivo que seria esse grande arcabouço de vidas, histórias, costumes, falas, significações e tantos outros, onde 
estamos imersos e somos capazes de contribuir e ao mesmo tempo trazer pra nós mesmos na forma de inconsciente pessoal, num processo constante de individuação, de construção de ser.

As questões espirituais fazem parte da vida psíquica das pessoas e Jung (2011) “queria entender o que realmente ocorre na alma das pessoas" (p. 582). Ele nos chama a atenção para força dos arquétipos que atravessam nossas vidas, indicando o "arquétipo da imagem de Deus” (Jung, 1994, p. 11) como um elemento constitutivo da nossa personalidade. Chama-nos, enquanto psicólogos, a estarmos atentos ao que não é do visível aos olhos, do essencial invisível aos olhos. A espiritualidade junguiana diz também desse não visto, mas que nos governa, principalmente quando não integrada.

Afinal de contas, a vida psíquica é em sua maior parte uma vida inconsciente e cerca a consciência de todos os lados: pensamento este suficientemente óbvio quando registramos a quantidade de preparação inconsciente necessária, por exemplo, para o reconhecimento de uma percepção dos sentidos. (Jung, 1934, p. 57)

Desta forma, Jung, sem usar do termo espiritualidade, nos fala do ser por trás do que se chama consciência. E Hopcke (2011) ainda nos acrescenta:

(...) A psique, como Jung a entendia, é melhor vista como a totalidade da vida não física, tanto racional quanto irracional, tanto pessoal quanto coletiva, tanto consciente quanto inconsciente. Esse modo de ver inclui na psique bem mais dos que os limitados fenômenos físico-racionalistas, entendidos como psicológicos antes de Jung, e abre espaço para aqueles aspectos da psique que vão além do pensamento da mente, como sensação, sentimento, intuição e instinto. (pp. 48-49)

Por fim, a meta da psicoterapia junguiana confunde-se com o processo de realização espiritual, “(...) visto que se nos atemos às experiências numinosas, somos libertados da maldição da patologia. Até mesmo a própria doença adquire um caráter numinoso" (Jung, 1973, p. 377). Neste sentido, a inclusão da espiritualidade na formação do psicoterapeuta poderia ser um elemento fundamental de promoção de saúde.

A psicologia transpessoal: a "quarta força" da psicologia e a espiritualidade

A Psicologia Transpessoal surge no cenário da história do movimento psicológico internacional nos anos 60 como um desdobramento e expansão da então nascente psicologia humanista. Abraham Maslow, um dos principais representantes e fundadores das duas abordagens, destaca este novo paradigma como a "quarta força" em psicologia, que foi precedi- da pelo behaviorismo ( $1^{\mathrm{a}}$ força), psicanálise ( $2^{\mathrm{a}}$ força) e pelo próprio humanismo ( $3^{\mathrm{a}}$ força), e aponta assim o seu surgimento.

Devo dizer que considero a Psicologia Humanista, ou terceira Força da Psicologia, apenas transitória, uma preparação para a Quarta Psicologia ainda "mais elevada”, transpessoal, transhumana, centrada mais no cosmo do que nas necessidades e interesses humanos, indo além do humanismo, da identidade, da individuação e quejandos. (Maslow, s/d, p. 12)

De acordo com Vich (1988) e mais recentemente (Taylor, 1996, p. 26), o termo "transpessoal" foi utilizado pela primeira vez por William James em uma palestra realizada em 1905 na universidade de Harvard, colocando-o segundo Scotton, Chinen e Battista (1996) como o pai da moderna psicologia transpessoal. Contudo está paternidade do termo pode ser dividida com Carl Jung ${ }^{1}$, pois como indica Daniels (2005), apesar de Jung não ter usado diretamente o termo transpessoal em seus escritos, o "inconsciente coletivo" é "überpersönlich" ou "além do pessoal”, o que de acordo com Strohl (1998) conduziu os tradutores ingleses e americanos de Jung, a partir de 1942, a usarem o termo überpersönlich como sinônimo de "transpessoal" para se referirem ao "inconsciente coletivo"2.

Em seu sentido original o "trans" foi agregado ao pessoal na palavra "transpessoal" para situar uma ampla gama de pesquisas que indicavam a dimensão espiritual ou o "principio da transcendência"3. O prefixo "trans" indica a inclusão da espiritualidade como dimensão constitutiva do fenômeno humano, recusando-se a uma adesão de um sentido religioso que deriva da relação dos humanos com a ideia de divindade, em um sentido teológico e que considera o espiritual como inacessível às coisas terrenas, pois seriam esferas totalmente distintas, manifestando uma relação de separação permanente. Assim,

A espiritualidade, ou a dimensão espiritual do homem, segundo tópico de nossa caracterização temática, identifica o movimento transpessoal como a primeira corrente da psicologia contemporânea que dedica atenção sistemática e privilegiada à dimensão espiritual da expe-

1 Jung introduz a palavra alemã überpersönlich na sua teoria psicológica na primeira publicação do artigo "A estrutura do inconsciente” em 1916, no qual über equivale à sobre, além e persönlich a pessoal, na edição brasileira (Jung, 1982, p. 133) optou-se pela palavra suprapessoal para traduzir este termo.

2 Schultz e Schultz (1994, p. 85), indicam que o inconsciente coletivo "Uberpersonliche (Transpersonal) Unconscious" é o deposito das experiências ancestrais.

3 O principio da transcendência "indicaria um impulso em direção ao despertar espiritual que perpassa a humanidade do ser, a própria pulsão de vida, morte e para além delas. $\mathrm{O}$ 'principio da transcendência’ envolve a natureza psicológica, descrita por Freud, ampliada por Maslow e por Weil.” (Saldanha, 2006, p. 109) 
riência humana, até então ignorada, negada, negligenciada ou reduzida a derivações secundárias de outras fatias inferiores do ser, como a sexualidade e a agressividade sublimadas (Boainain Jr., 1998, p. 50).

A espiritualidade na psicologia transpessoal apresenta um aspecto integrativo do transcendente/ imanente que marca uma compreensão integral do ser humano, de forma que este termo não se refere a uma visão transcendental, mas, ao tornar-se "MAIS PESSOA" (Wilber, 1996, p. xviii), assumindo-se radicalmente toda a abertura, incompletude e amplitude do Ser Humano.

Para Bezerra (2012), o hiato entre transcendência e imanência no estudo da espiritualidade, assim como, as diversas divisões tomadas pelo senso comum como auto-existentes, são profundamente questionadas pela psicologia transpessoal. Nesta concebe-se a possibilidade de um "entre-deux" nestes aspectos, bem como nas múltiplas interfaces humana ${ }^{4}$, sem, no entanto, bipartir a concepção de existência. Para o filósofo francês Merleau-Ponty, a identificação desse círculo abriu um espaço entre o homem e o mundo, entre o interno e o externo. Esse espaço não era um abismo ou divisor: ele englobava a distinção entre homem e mundo e, ainda, provia a continuidade entre eles. Sua abertura revela-se como um caminho do meio, um entre-deux. Assim, no prefácio de sua Fenomenologia da Percepção, ele escreve:

Comecei a refletir, minha reflexão é sobre um irrefletido; ela não pode ignorar-se a si mesma como acontecimento, logo ela se manifesta como uma verdadeira criação, como uma mudança de estrutura da consciência, e cabe-lhe reconhecer aquém de suas próprias operações, o mundo que é dado ao sujeito, porque o sujeito é dado a si mesmo (...). A percepção não é uma ciência do mundo, não é nem mesmo um ato, uma tomada de posição deliberada; ela é o fundo sobre o qual todos os atos se destacam e ela é pressuposta por eles. O mundo não é um objeto do qual possuo comigo a lei de constituição; ele é o meio natural e o campo de todos os meus pensamentos e de todas as minhas percepções explícitas. (Merleau-Ponty, 1999, pp. 5-6).

Mais adiante, no final dessa mesma obra, ele acrescenta: "O mundo é inseparável do sujeito, mas de um sujeito que não é senão projeto do mundo, e o sujeito é inseparável do mundo, mas de um mundo que ele mesmo projeta” (Merleau-Ponty, 1999, p. 576). Esta visão de espiritualidade considera o sujeito "in-

\footnotetext{
4 Wilber (2000, p. 27) destaca cinco dimensões básicas: "matéria, corpo (no sentido de corpos vivos e vitais, o nível emocional-sexual), mente (incluindo imaginação, concepções e lógica), alma (a fonte da identidade supra-individual) e espírito (tanto o fundamento sem forma como a união não-dual de todos os outros níveis)”.
}

separável do mundo", que, neste trabalho denominamos de trancendente/imanente ou como indica Ferry (2010, p. 211) em homenagem ao fenomenólogo Husserl: "transcendência na imanência". Este conceito de inseparatividade, como o cerne da espiritualidade, foi desenvolvido e integrado pelas tradições não duais do Oriente, como também é marco do referencial teórico da fenomenologia e da abordagem transpessoal, e defendem a tese de que a dualidade mente/corpo surgiu da ignorância sobre a natureza das relações do organismo humano com o ambiente.

Para psicologia transpessoal essa forma de refletir a espiritualidade marca radicalmente a virada do pensamento fenomenológico como uma busca de retorno ao mundo existencial, sendo um golpe nas ideias do "trans" como um simples "além de" abstrato e teológico, pois o mundo é preexistente à reflexão mas não separado de nós, conforme destacado por Varela, Thompson e Rosch (2003):

(...) as mentes despertam em um mundo. Não projetamos nosso mundo. Nós simplesmente nos descobrimos com ele; nós despertamos tanto para nós mesmos quanto para o mundo que habitamos. Vimos a refletir sobre esse mundo à medida que crescemos e vivemos. Nós refletimos sobre um mundo que não é feito, mas encontrado, e é também nossa estrutura que nos possibilita refletir sobre esse mundo. Então, ao refletirmos, nós nos encontramos em um círculo: estamos em um mundo que parece que já existia antes da reflexão ter-se iniciado, mas esse mundo não é separado de nós (p. 21).

A espiritualidade é posta como um convite permanente para olharmos de maneira interdependente o aqui-e-agora do mundo vivido, desafiando-nos a percebermos este mundo vivido como solo primeiro dos nossos sentidos, incluindo nossa abertura para o mundo e desafiando a ideia de que a verdade "habita apenas o 'homem interior', ou antes não há homem interior, o homem está no mundo e é no mundo que ele se conhece" (Merleau-Ponty, 1999, p. 6). O trans "mais pessoal" trata a espiritualidade como a possibilidade de Ser expressa no mundo, mas que conserva sua abertura, sua impossibilidade de fechar-se, seu "ir além".

A psicologia transpessoal como um estilo de pensamento que revela o "mistério" do inacabamento do humano, assume a sua própria incapacidade de dizer tudo o que há para ser dito, aproximando-se do pensamento de Merleau-Ponty (1999) quando afirma:

Será preciso que a fenomenologia dirija a si mesma a interrogação que dirige a todos os conhecimentos; ela se desdobrará então indefinidamente, ela será, como diz Husserl, um diálogo ou uma meditação infinita, e, na medida em que permanecer fiel à sua intenção, não saberá 
onde vai. O inacabamento da fenomenologia e o seu andar incoativo não são signo de um fracasso, eles eram inevitáveis porque a fenomenologia tem como tarefa revelar o mistério do mundo e o mistério da razão (p. 20).

Assim, é como um pensamento aberto à interrogação permanente e que trabalha para não se fechar nos dogmatismos e absolutismos, que se caracteriza a psicologia transpessoal; sendo a espiritualidade reveladora de um projeto de formação humana que não cessa de ampliar, pois revela o inacabamento do humano (Silva, 2016).

\section{Metodologia}

\section{O processo de construção do fenômeno}

A pesquisa segue uma perspectiva qualitativa de cunho fenomenológico conforme proposta por Bicudo (2000, 2011). E assume uma postura:

(...) consoante com discursos que promulgam a inseparabilidade entre sujeito e objeto, a impossibilidade de se ter apenas um modo de ver o estudado, bem como com a relevância do contexto histórico, político e social em que o estudado se situa e com a impossibilidade de aprisionar-se o dito na linguagem em caixas de interpretação (Bicudo, 2011, p. 20).

Nessa perspectiva, a realidade não é considerada independente do sujeito que a vivencia, onde o fenômeno é visto como um objeto posto objetivamente em um mundo exterior, podendo ser observado, experimentado, manipulado, contado ou medido por um observador neutro. De outro modo, no processo de conhecer fenomenológico, o fenômeno é

(...) o que se mostra no ato da intuição efetuado por um sujeito individualmente contextualizado, que olha em direção ao que se mostra de modo atento e que percebe isso que se mostra nas modalidades pelas quais se dá a ver no próprio solo em que se destaca como figura de um fundo. A figura, delineada como fenômeno e fundo, carregando o entorno em que o fenômeno faz sentido (Bicudo, 2011, p.30).

Mostra-se aqui uma posição de interação entre aquele que percebe o fenômeno e o que se dá a perceber deste fenômeno no movimento de sua compreensão, de seu conhecimento. Conhecimento que, no universo da Fenomenologia, tem como ponto de partida o voltar-se "às coisas mesmas”. Entendendo a "coisa mesma" como fenômeno, do qual temos acesso imediato e uma intuição originária. "O fenômeno integra a consciência e o objeto, unidos no próprio ato de significação” (Forghieri, 1993, p.15). Do ponto de vista operacional contemplou três momentos descritos a seguir:

O $1^{\circ}$ Momento, contato com o fenômeno investigado a partir de uma atitude fenomenológica de Abertura e Interrogação, ou seja, perguntas norteadoras foram lançadas para que os participantes discorressem sobre o fenômeno investigado. As entrevistas semi-estruturadas foram gravadas com a permissão dos entrevistandos para posterior transcrição, seguindo os devidos trâmites éticos, com assinatura de um Termo de Compromisso Livre e Esclarecido - TCLE.

A entrevista, dentro desta perspectiva, surge como um diálogo, pois o pesquisador: “... está sempre situado, individualizado e é por isto que necessita do diálogo; entrar em comunicação com outras situações (vividas e relatadas por outros filósofos ou outros homens) é a maneira mais segura de ultrapassar seus limites" (Merleau-Ponty, 1973, p.24). Assim, o diálogo com os participantes ocorreu de acordo com suas disponibilidades de tempo e local. O $2^{\circ}$ Momento, Descrição Fenomenológica, consistiu na transcrição das entrevistas dos sujeitos. Utilizamos a linguagem dos participantes de forma a termos um registro que possibilitasse apreendermos as experiências dos psicólogos sobre espiritualidade. No $3^{\circ}$ Momento, Análise fenomenológica dos dados, após a transcrição, cada entrevista foi submetida, individualmente, aos seguintes procedimentos: a) Leitura Geral; b) Redução em Unidades de Significado (US) que segundo Bicudo (2000) “(...) são unidades da descrição ou do texto que fazem sentido para o pesquisador a partir da interrogação formulada” (p. 81); c) Encontro de Categorias Abertas que são vistos como “(...) constructos que apresentam grandes convergências de Unidades de Significado já analisados e interpretados. Indicam os aspectos estruturantes do fenômeno investigado e abrem-se à metacompreensão considerando a interrogação, o percebido, o analisado, o diálogo estabelecido na intersubjetividade auto/sujeitos/autores/região de inquérito" (Bicudo, 2000, p. 82).

Ao final deste processo, organizamos as Unidades de Significados a partir das convergências, de maneira que chegamos a dois grandes blocos de categorias abertas: o primeiro foi "Múltiplas espiritualidades" que congregam três redes de unidades de significados sobre a visão dos participantes sobre a espiritualidade e o segundo bloco, "A compreensão da espiritualidade na prática clínica”, congrega unidades de significado que falam sobre o manejo da temática espiritualidade pelos terapeutas investigados.

\section{Participantes}

Fizemos entrevistas com 4 (quatro) psicólogos junguianos e 4 (quatro) psicólogos transpessoais. Para contextualizar e termos indícios de onde os psicólogos entrevistados falam, conheçamos um pouco de cada um deles (todos os nomes são fictícios): Sara é psicóloga e especialista em teoria e prática junguiana; Lavínia é psicóloga junguiana, especialista em Teoria 
e Prática Junguiana e Arteterapeuta; Bruna é psicóloga junguiana e arteterapeuta; Luy é psicólogo junguiano e mestrando em Psicologia; Núbia é psicóloga transpessoal, pedagoga, especialista em psicologia transpessoal, psicologia social e psicologia da educação, hipnoterapeuta e abordagem sistêmica; Solange é psicóloga transpessoal, facilitadora de grupos de Pathwork; Laura é psicóloga transpessoal e Luana é psicóloga transpessoal.

\section{Apontamentos e perspectivas acerca da espiritualidade}

\section{Múltiplas Espiritualidades}

Nesta grande categoria aberta, agregamos as visões dos participantes sobre espiritualidade.

\section{Espiritualidade como energia interna, acesso ao Eu superior/Self}

A entrevistada Bruna diz que espiritualidade é "uma (...) energia dentro de mim, assim, universal, sentir que eu posso me apegar a isso", a seguir indica que: "Enquanto eu tiver perdida, eu vou poder me centrar nisso e poder me achar de alguma forma”.

$\mathrm{Na}$ fala de Bruna vemos algo que sinaliza para a compreensão de espiritualidade como um acesso ao que é de ordem do interno, energia interna, mas que ao mesmo tempo é universal e transcende o eu, por isso fazemos a correlação com o Eu superior, termo junguiano, que, quase que como sinônimo de Deus é algo que transcende o que é de ordem do ego e acessa o Self, esse "supra-eu”.

Lavínia, outra psicóloga entrevistada, diz que a espiritualidade é algo que ela confunde “(...) um pouco a coisa, anima, alma e espírito assim. Eu acho que essas coisas estão tão (...), eu não coloco em caixinhas.” Vai para além do que é possível enquadrar e nomear. E quando indagada sobre o que acha da relação espiritualidade e saúde diz: "Eu acho que ela é a própria saúde”. Não fazendo nenhuma diferenciação no que é de ordem espiritual e a saúde. Bruna aponta como guia: "Quando a pessoa tem esse eixo dentro de si. De entrar em contato com essa energia e que vai tá guiando ela”. A espiritualidade guia o curso da saúde. Vejamos o que Hopcke (2011) falou acerca dos estudos de Jung no que diz respeito ao espírito:

Na tentativa de compreender os escritos de Jung sobre o espírito, enfrentamos o mesmo problema que Jung em sua tentativa de captar o que a palavra espírito designa. Quando se alcança uma explicação promissora, percebe-se que o apreendido escapa rapidamente por entre os dedos de nossa rede intelectual, sendo levado pelo mar bravio de importantes, mas de difícil entendimento, aspectos da experiência humana. Por isso Jung aborda o espírito da mesma maneira com que trata os muitos habitantes desconcertantes de seu mar experimental, isto a partir de sua posição como psicólogo. Ele não está a fim, conforme confessa, ou não é capaz de discussões filosóficas ou teológicas sobre a natureza do espírito. Ele volta-se, antes, para a fenomenologia do espírito na vida psíquica: o que o espírito mostra que é, e em que aspectos ele é igual ou diferente da psique/alma. (p. 53)

Segundo este mesmo autor, Jung foca seus estudos sobre alma, psique e espírito muito mais na experiência em si do que na filosofia dos termos. Fazendo a correlação com o que a psicóloga Sara diz: "De repente (...) Eu acho que você tá em contato com a espiritualidade acho que é sinônimo de saúde", vê-se um pouco desse não filosofar, mas sentir. Dentro dessas ideias, portanto, ter acesso ao que se compreende por espiritualidade é acessar saúde, lembramos que não significa que não exista doença, o corpo físico pode adoecer, o corpo psíquico pode adoecer, mas se há uma ligação com o que aquele ser entende por espiritualidade pode estar em estado saudável.

\section{Religare: acessar o que transcende sem necessaria- mente ter religião}

A psicóloga Núbia indica que a “(...) espiritualidade diz respeito a uma dimensão para além do nível material, para além do físico, visível e quantificável." Solange diz: "(...) é o contato com a essência que a gente é”. Continua falando da conexão com: "esse eu que nos unifica com tudo, então é quando a gente se recolhe pra ir pra esse centro interno, que é o centro do universo, quando a gente busca esse centro interno, a gente tá buscando o centro do universo". Ligar-se com esse centro que tem referência interna, mas não se separa do externo, que talvez nem exista essa separação, sendo esta apenas consequência de um modelo de ciência.

As práticas científicas lidam quase que exclusivamente com a ordem explicada por meios e métodos também explícitos. Como regra geral, tais práticas consideram os processos físicos como primários quando na verdade eles são secundários. Quando isso ocorre cria-se o reducionismo e a ciência confunde o entendimento e o conhecimento necessários para elaborar uma Teoria do Tudo bem-sucedida. Confusões desse tipo sempre surgem devido a uma dependência exclusiva de práticas explícitas, que continuamente se desviam por omissão ou negligência, da realidade unificadora e fecunda da ordem implícita subjacente. (Lohrey, 2004, p.82)

O acesso ao complexo das coisas é urgente para psicologia que enfrenta o aumento da violência e sofrimentos motivados por conflitos religiosos, principalmente o aumento do fundamentalismo radical. A psicologia como cuidadora do humano tem tarefas a cumprir no que diz respeito a esse debate, não pode- 
mos nos subtrair estes conhecimentos (CRPSP, 2016). Situamos uma postura laica que permita aos profissionais o acesso ao manejo desta temática no campo profissional.

Uma das psicólogas entrevistadas destaca “(...) a espiritualidade num sentido de você respeitar o que vem”. Aceitar o outro e a outra no momento que ele se apresenta. Ela continua: “(...) eu entendo espiritualidade essa coisa mesmo da humanidade, de você se colocar no lugar do outro, que a psicologia fala muito sobre isso, mas que poucos terapeutas colocam em prática” (Bruna). E conclui a fala nesse sentido dizendo: "Mas a espiritualidade vem nesse sentido, vem, na aceitação, vem no não julgamento, não sou nenhuma santa, não, isso é um exercício diário”. Fala de seus limites, mas aponta as necessidades de ser, ser plenamente para o outro. Temos, assim, a espiritualidade inseparável do cotidiano e construtora de saúde mental pela melhora da autoestima e ampliação da aceitação de si.

\section{Espiritualidades e promoção de saúde}

As experiências espirituais perpassam a vida vivida dos entrevistados que acabam buscando incluí-las como elementos propiciadores de saúde. Solange nos diz que:

Esse percurso, eu acredito que vai nos conduzir para um maior equilíbrio emocional, maior clareza que diminui os conflitos internos, o conflito vem da dualidade, vem da visão separatista. (...) quando a gente se conecta com a dimensão da totalidade, a gente lembra que a gente não é só aquilo. (...) a gente (...) que não se sente tão ameaçado porque a gente sabe que a gente é um todo. (...) esse conflito vai minimizando e a gente vai dissolvendo o conflito, e isso gera saúde e a gente pára de brigar com a gente mesmo.

A vivência da espiritualidade através da integração das dualidades parece oferecer sentido, e consequentemente promoção de saúde, pois este processo “(...) vai pacificando internamente, esse movimento gera a paz fora de nós, primeiro a gente faz o movimento de compaixão e amor com a gente mesmo pra poder fazer depois fora de nós. Isso vai sendo uma onda silenciosa que vai sendo propagada, que vai pela sociedade (...)" (Luy).

Luana complexifica a visão de saúde e indica que "Dentro dessa concepção de saúde fica explicitado que a espiritualidade é fator preponderante na promoção da saúde do indivíduo” enquanto Bruna destaca sua influência na saúde quando diz:

Acho que interfere positivamente, né? Quando a pessoa tem esse eixo dentro de si. De entrar em contato com essa energia e que vai tá guiando ela. (...) exista um (...) uma vivência negativa naquele momento, mas tem essa questão luminosa que tá sagrada, que tá fazendo ela de alguma forma reagir, tendo contato com isso.

A psicóloga Lavínia toma a espiritualidade como saúde e ao mesmo tempo como uma dimensão constitutiva do processo de sua promoção:

Eu acho que ela é a própria saúde, é um aspecto de saúde. (...) é, eu vejo isso como uma espécie de saúde não somente, assim, somente, espiritualidade, tá entendendo, isso é de uma forma equilibrada que você vai precisar, tá aqui, viver, e você vai precisar também se reconectar e fazer essa ponte.

O que colabora com a ideia de teóricos do campo da psicologia (Ancona-Lopez, 2008b; Angerami-Camon, 2008; Cavalheiro \& Falcke, 2014) para quem a introdução desta temática na formação destes profissionais poderia ajudá-los a integrar as suas próprias experiências espirituais, provendo assim, mais saúde.

Para Sara, a vivência da espiritualidade conduz a "uma espécie de leveza” e “(...) esta em contato com o sagrado, é estar mais próximo da tua essência, é estar em caminho de saúde", ou seja, a presença deste fenômeno na vida profissional parece melhorar a qualidade de vida, pois oferece um sentido de vida capaz de se contrapor às dificuldades que surgem neste campo de trabalho.

A visão de que espiritualidade é saúde, está presente na fala tanto de psicólogos junguianos, como na dos transpessoais, o que sugere que não é possível dissociar saúde de espiritualidade sem que estejamos criando espaço para o surgimento do sofrimento psíquico. De forma geral, as espiritualidades, e não mais a espiritualidade, despontam como condição sine qua non para que haja saúde, assim como aponta a importância da introdução desta temática na formação dos profissionais de saúde.

A compreensão da espiritualidade na prática clínica Nesta grande categoria aberta incluímos a ideia de espiritualidade dentro da prática clínica. Tentamos agregar as falas e posicionamentos que apontam para o manejo deste tema no setting terapêutico. A demanda precisa vir do cliente/paciente? Ou ela pode ser trazida pelo terapeuta como parte de sua rede de crenças e desejos?

A espiritualidade no processo terapêutico: demanda do cliente e/ou dimensão contextual do terapeuta?

Todos os entrevistados estão dispostos a tratar a temática da espiritualidade no processo terapêutico a partir da demanda do cliente, indicando uma flexibilidade e abertura para um campo usualmente não explorado ao longo da formação profissional. "Quando 
é necessário até lhe indago como é sua relação com Deus, pois se a gente pergunta qual a sua religião, já se estabelece um certo recuo a até desconfiança”. (Entrevista com Luana)

Contudo, uma marca diferencial no manejo da espiritualidade na clínica aparece entre os participantes ao longo das entrevistas. As psicólogas transpessoais entrevistadas por considerarem a espiritualidade uma dimensão constitutiva da subjetividade humana, a inclui espontaneamente e intencionalmente no processo terapêutico, sendo esta vista como parte de um contexto mais amplo no qual a complexidade do humano esta envolvida. Assim a espiritualidade, enquanto busca de sentido mais amplo para o existir, aparece nos modos de ser do terapeuta, conforme podemos perceber nas falas a seguir:

Acrescento ainda que é fundamental a inclusão da espiritualidade na prática terapêutica e na vida. (Núbia)

A gente traz isso verbalmente para o cliente de uma forma cuidadosa, de acordo com a receptividade de cada um. (Solange)

Sim. Abordo estas questões da espiritualidade como parte da vida do cliente, sem doutrinações ou coisas religiosas. (Laura)

Para estas psicólogas, a espiritualidade é contextual, ou seja, inerente ao humano e é vista como um fator que pode ajudar na promoção de saúde, assim como o cuidado com as emoções e o corpo. O contextual é apresentado como uma rede de crenças e desejos que oferecem um background capaz de sustentar as experiências que constituem a subjetividade do sujeito (Vaughan \&Walsh, 1995, 1997). Em última instância é a própria consciência do terapeuta. Os psicólogos junguianos entrevistados só tratam da temática caso ela seja trazida expressamente pelo cliente, conforme podemos perceber nas falas a seguir:

Mas as pessoas geralmente, trazem isso, e aí sim é abordado (...). (Bruna)

Assim, se, você, assim se o terreno não for fértil ou for, isso pode vir a surgir e se desdobrar em outra abordagem ou com outra pessoa talvez isso não seja (...), mas eu deixo a coisa acontece, não trago, deixo a coisa acontecer. (Lavínia)

O psicólogo Luy reforça esta ideia quando aponta que o trabalho com a temática da espiritualidade não faz parte de sua metodologia de trabalho, contudo percebe que sua emergência favorece a ampliação do processo terapêutico, como podemos ver em sua fala a seguir: "Como método ou objetivo de trabalho não, mas acho bastante interessante quando o tema vem à tona, pois é um assunto que leva a lugares profundos, e por vezes não explorados, dos clientes." (Luy). Por fim, Sara destaca que a temática da espiritualidade “(...) surge na clínica bastante”, sendo portanto bas- tante explorada na psicoterapia junguiana.

Estas perspectivas apontam para importância do processo de formação dos psicólogos no manejo da temática espiritualidade, pois vemos como os modelos de subjetividade e realidade, subjacentes as abordagens, influenciam diretamente na prática clínica. Neste sentido Coliath (2007) discute as implicações da exclusão da temática espiritualidade pelas universidades, enquanto Ancona-Lopez (1999, 2008) problematiza a ausência de eixos teóricos e reflexões que permitam um suporte no manejo no contato com o mundo vivido dos clientes quando do surgimento deste fenômeno. Além da necessidade de ampliarmos as pesquisas das implicações éticas deste manejo e de lidarmos com os sofrimentos decorrentes dos desvios promovidos nesta área (Koenig, 2005).

As entrevistas indicam que ambas abordagens tratam desta temática na clínica, embora, compreendam de forma aproximada o que seria a espiritualidade, ou espiritualidades. As reflexões teóricas destas abordagens parecem operar como lentes capazes de ajudar os terapeutas no processo de acolhimento deste fenômeno no âmbito da clínica, assim como oferecem caminhos que ajudam a nortear o processo de cura.

Durante as entrevistas com todos os participantes pareceu-nos fundamental o respeito à diversidade de modos de existir dos clientes, apontando um cuidado ético para com a existência humana e respeito às múltiplas expressões das espiritualidades. Como nos indica Angerami-Camon (2003): "Falar em acompanhamento espiritual não é pedir a alguém para ter esta ou aquela atitude religiosa; tampouco ter uma experiência transcendental. É acompanhar aquela pessoa com respeito e confiança” (p. 15). Este aspecto pareceu-nos fundamental, pois independente das escolhas teóricas, o trabalho do psicólogo deveria pautar-se num exercício de profundo respeito pela singularidade e alteridade do outro.

\section{Algumas considerações gerais}

A espiritualidade enquanto uma busca pessoal de respostas sobre o significado da vida e o relacionamento com o sagrado e/ou transcendente desponta como um elemento fundamental nas agendas de promoção de saúde. Como indicamos, os estudos no campo psicológico destacam a importância deste elemento no processo de formação e compreensão integral do ser.

Os processos de fragmentação instituídos na modernidade parecem ainda reverberar nas mentes daqueles que pensam a ciência como neutra e ausente de sentido, assim como estabelecem fronteiras rígidas entre esta e a espiritualidade. A complexidade deste momento histórico tem requerido perspectivas mais inclusivas na tentativa de curar a ferida cartesiana, sendo a ciência questionada do seu lugar absoluto, assim como a espiritualidade vai distanciando-se das visões dogmáticas.

Indicamos que a visão que os participantes têm 
de espiritualidade segue muito mais no rumo das espiritualidades, do que de uma espiritualidade ou mesmo de uma religião. As espiritualidades apresentam-se diversas como aponta a bibliografia, contudo temos uma convergência das espiritualidades como promotora de saúde, e posta como fundamental para compreensão da integralidade do ser.

As espiritualidades, segundo nossos entrevistados são: energia interna; força superior; re-conexão da matéria com algo além dela ao passo que dá sentido à matéria; eu superior (Self), conexão com o Self; integração com o todo e com o mistério que há em nós; é diferente de religião, mas não precisa exclúi-la; é tudo que atrai o ser; aproximar-se de um centro, contato com a essência que somos; saúde; aceitação incondicional; humanidade; intuição; transcendência; algo da ordem do pré-humano, atributo do humano; equilíbrio e unicidade.

Essas visões de espiritualidades são tratadas pela Psicologia Junguiana e a Psicologia Transpessoal dentro de suas perspectivas teóricas e práticas. De formas diferentes e partindo de pontos não exatamente equivalentes, Jung trata do contato com o Self, deste Eu que é superior e que precisa ser acessado para uma compreensão de si. Enquanto que a Psicologia Transpessoal propõe que nos conectemos com o Todo indissociável em que estamos imersos, que não há separação entre eu e outro, somos uma teia de interdependências.

Para tanto, na questão prática, dentro do processo clínico, essas duas teorias orientam tratar da temática dentro do setting clínico. No que diz respeito à prática orientada pela teoria junguiana a demanda precisa vir do cliente. Não é algo que as psicólogas e psicólogo entrevistados apontem como trazido por elas e ele na clínica, é preciso que o cliente traga a questão. Enquanto as psicólogas transpessoais tratam espontaneamente e intencionalmente da temática na clínica, pois a compreendem como dimensão humana e portanto inseparável do cuidado clínico. Neste sentido a espiritualidade é tida como contextual.

Ambas as abordagens destacam a importância da temática da espiritualidade no processo de promoção de saúde e buscam tratá-la de maneira ética com seus clientes. Apontamos a necessidade de ampliação de pesquisas que apontem as implicações éticas do manejo da espiritualidade na clínica, além de uma melhor delimitação das convergências e divergências entre espiritualidade, religião e religiosidade e suas implicações no processo de formação dos psicólogos.

\section{Referências}

Ancona-Lopez, M. (1999). Religião e Psicologia Clínica: quatro atitudes básicas. In Massimi, M. \& Mafhfoud, M. (Org.). Diante do Mistério: Psicologia e Senso religioso. São Paulo: Ed. Loyola.
Ancona-Lopez, M. (2008). Religião na constituição da subjetividade: psicólogos e seus clientes. In V. A. Angerami (Org.), Psicologia e religião (pp.69-84). São Paulo: Cengage Learning.

Angerami-Camon, V. A.; Chiattone, H. B. C., Sebastiani, R. W., Fongare, M. L. H. \& Santos, C. T. dos. (2003). E a Psicologia entrou no hospital. São Paulo: Pioneira Thompson Learning, 2003

Angerami-Camon, V. A. (2008). Religiosidade e psicologia: a contemporaneidade da fé religiosa nas lides acadêmicas. In V. A. Angerami (Org.), Psicologia e religião (pp.1-42). São Paulo: Cengage Learning.

Bezerra, M. A. (Org). (2012). Tratado de Psicologia Transpessoal: antigos ou novos saberes em psicologia? Volume 1. Natal, RN: EDUFRN.

Bicudo, M. A. V. (Org.). (2000). Fenomenologia: confrontos e avanços. São Paulo: Cortez.

Bicudo, M. A. V. (Org.). (2011). Pesquisa qualitativa: segundo a visão fenomenológica. São Paulo: Cortez.

Boainain Jr, E. (1998). Tornar-se Transpessoal: Transcendência e Espiritualidade na Obra de Carl Rogers. São Paulo: Summus.

Cavalheiro, C. M. F. \& Falcke, D. (2014). Espiritualidade na formação acadêmica em psicologia no Rio Grande do Sul. Estudos de Psicologia (Campinas), 31(1), 35-44. https://dx.doi.org/10.1590/ 0103-166X2014000100004.

CRPSP - Conselho Regional de Psicologia de São Paulo. (2016). Psicologia, Laicidade e as Relações com a Religião e a Espiritualidade. Vols. 1, 2 e 3. São Paulo: CRP-SP.

Coliath, A. A. M. (2007). Escolha do Terapeuta Associada a Denominação Religiosa. Dissertação de Mestrado da Pontifícia Universidade Católica de São Paulo, São Paulo.

Dal-Farra, R. A. \& Geremia, C. (2010). Educação em Saúde e Espiritualidade: Proposições Metodológicas. In Revista brasileira de educação médica, 34 (4): 587-597; 2010, p. 589)

Daniels, M. (2005). Shadow, Self, Spirit: Essays in Transpersonal Psychology. Exeter \& Charlottesville, VA: Imprint Academic.

Dunne, C. (2012). Carl Jung: curador ferido de almas. São Paulo: Alaúde Editorial.

Ferry, L. (2010). Aprender a viver: filosofia para os novos tempos. Rio de Janeiro: Objetiva.

Forghieri, I. C. (Org.). (1993). Fenomenologia e psicologia. São Paulo: Cortez. 
Foucault, M. (2006). A hermenêutica do sujeito. São Paulo: Martins Fontes.

Freitas, M. H. \& Vilela, P. R. (2017). Leitura Fenomenológica da religiosidade: implicações para o psicodiagnóstico e para a práxis clínica psicológica. Revista da Abordagem Gestáltica - Phenomenological Studies, 23 (1), 95-107.

IBGE - Instituto Brasileiro de Geografia e Estatística (2012). Censo Demográfico 2010: Características gerais da população, religião e pessoas com deficiência. Rio de Janeiro.

Hopcke, R. H. (2011). Guia para a obra completa de C. G. Jung. Rio de Janeiro: Ed. Vozes.

Jung, C. G. (1934). Os arquétipos e o inconsciente coletivo. Petrópolis: Ed. Vozes.

Jung, C. G. (1973). C. G. Jung Letters (Vol. 1). Princeton: Princeton University Press.

Jung, C. G. (1982). O eu e o inconsciente. Obras completas de C.G.Jung Vol VII/2. Petrópolis: Vozes.

Jung, C. G. (1994). Psicologia e alquimia. Petrópolis: Ed. Vozes.

Jung, C. G. (1995). Psicologia e Religião. Petrópolis: Vozes.

Jung, C. G. (1998). O Homem e seus Símbolos. Rio de Janeiro: Nova Fronteira.

Jung, C. G. (2006). Memórias, sonhos e reflexões. Rio de Janeiro: Nova Fronteira.

Jung, C. G. (2011). Freud e a psicanálise. Petrópolis: Vozes.

Koenig, H. G. (Org.). (2005). Espiritualidade no cuidado com o paciente. Por quê, como, quando e o quê. São Paulo: Editora FE.

Lohrey, A. (2004). Simetria: A Teoria do Tudo. In Di Biase, F. \& Amoroso, R. A revolução da consciência: Novas descobertas sobre a mente do século XXI. Petrópolis: Ed. Vozes.

Merleau-Ponty, M. (1973). Ciências do homem e fenomenologia. São Paulo: Saraiva.

Merleau-Ponty, M. (1999). Fenomenologia da percepção. São Paulo: Martins Fontes.

Maslow, A. (s/d). Introdução à Psicologia do Ser. Rio de Janeiro: Eldorado.

Moreira-Almeida, A. (2010). O crescente impacto das publicações em espiritualidade e saúde e o papel da Revista de Psiquiatria Clínica. Archives of Clinical Psychiatry (São Paulo), 37(2), 41-42.
Panzini, R. G., Rocha, N. S., Bandeira, D. R. \& Fleck, M. P. de A. (2007). Qualidade de vida e espiritualidade. Rev. Psiq. Clín. 34 (supl.1), 105-115.

Peres, J. F. P.; Simão, M. J. P. \& Nasello, A. G. (2007). Espiritualidade, religiosidade e psicoterapia. Revista de Psiquiatria Clínica, 34 (supl 1), 136145.

Saldanha, V. (2006). Didática transpessoal: perspectivas inovadoras para uma educação integral. Campinas, SP: [s.n.].

Schultz, D. \& Schultz, S. E. (1994). Theories of personality. Pacific Grove, CA: Brooks/Cole.

Scotton, B., Chinen, A. \& Battista, J. (1996). Textbook of Transpersonal Psychiatry and Psychology. New York, New York: Basic Books.

Strohl, J. (1998). Transpersonalism: Ego Meets Soul. Journal of Counseling and Development, 76, 397-403.

Taylor, E. (1996). William James and transpersonal psychiatry. In B. Scotton, A. Chinen \& J. Battista (Eds.), Textbook of Transpersonal Psychiatry and Psychology (p. 21-28). New York: Basic Books.

Varela, F., Thompson, E. \& Rosch, E. (2003). A mente incorporada: ciências cognitivas e experiência humana. Porto Alegre: Artmed.

Vasconcelos, E. M. (2009). Espiritualidade na educação popular em saúde. Cad. Cedes, Campinas, vol. 29, n. 79, p. 323-334, set./dez. 2009.

Vaughan, F.; Walsh, R. N. (1995). Além do ego: dimensões transpessoais em Psicologia. São Paulo: Ed. Cultrix/Pensamento.

Vaughan, F.; Walsh, R. N. (1997). Caminhos além do ego: uma visão transpessoal. São Paulo: Ed. Cultrix.

Vich, M. A. (1988). Some historical sources for the term "transpersonal". Journal of Transpersonal Psychology, 20, 107-110.

Xavier, M. (2006). O conceito de religiosidade em C. G. Jung. Psico, 37 (2), 183-189.

Wilber, K. (1996). O espectro da consciência. São Paulo: Ed. Cultrix.

Wilber, K. (2000). Integral psychology: consciousness, spirit, psychology, therapy. Boston: Shambhala Publications. 
Aurino Lima Ferreira (https://orcid.org/0000-00027883-9549) é Professor Associado (Departamento de Psicologia e Orientação Educacionais), Pesquisador e Professor do Núcleo Educação e Espiritualidade do Programa de Pós-graduação em Educação da Universidade Federal de Pernambuco. Endereço Institucional: Rua Jacaraú 25b, Ilha Joana Bezerra, CEP 50080-380. Recife - Pernambuco. Email: aurinolima@gmail.com

Laila Anine Candida da Silva (https://orcid.org/00000002-5677-3876) é Doutoranda em Educação pelo Programa de Pós-Graduação em Educação da Universidade Federal de Pernambuco, Mestra em Educação e Graduação em Psicologia pela UFPE. Psicóloga Escolar em Jaboatão dos Guararapes/PE. Email: lailaanine@gmail.com

Sidney Carlos Rocha da Silva (https://orcid. org/0000-0001-8561-5378) tem Licenciatura em Psicologia e Mestrado em Educação, e é Doutorando do Programa de Pós-Graduação em Educação da Universidade Federal de Pernambuco. Atualmente é
Professor Substituto do Departamento de Psicologia e Orientação Educacional da UFPE; Coordenador do Núcleo Educacional Irmãos Menores de Francisco de Assis (NEIMFA) na comunidade do Coque-Recife. Email: mahasido16@yahoo.com.br

Marlos Alves Bezerra (https://orcid.org/0000-00030605-7297) é Graduado em Psicologia, Mestre e Doutor pelo Programa de Pós-Graduação em Ciências Sociais da Universidade Federal do Rio Grande do Norte (área de concentração cultura e representações). Estágio Pós Doutoral (PRODOC/CAPES) pelo programa de pós-graduação em psicologia da UFRN(PPGPSi). Professor Adjunto III no Departamento de Psicologia da UFRN e do Programa de Pós-graduação em Psicologia da mesma instituição. Email: marlosdoc@ yahoo.com.br
Recebido em 13.06.2017

Primeira Decisão Editorial em 06.11.2017

Aceito em 03.04.2019 